International Journal of Engineering \& Technology, $7(2.7)(2018) 308-311$
SPC
International Journal of Engineering \& Technology
Website: www.sciencepubco.com/index.php/IJET
Research Paper

\title{
Smart agriculture monitoring system using IoT
}

\author{
P. Lashitha Vishnu Priya ${ }^{1 *}$, N. Sai Harshith ${ }^{1}$, Dr. N. V. K. Ramesh ${ }^{2}$ \\ ${ }^{1}$ B.Tech student, Department of Electronics and Computer Science Engineering, KLEF \\ ${ }^{2}$ Associate Professor, Department of Electronics and Computer Science Engineering, KLEF, \\ Green Fields, Vaddeswaram, Guntur, Andhra Pradesh 522502 \\ *Corresponding author E-mail: lashitha.04@gmail.com
}

\begin{abstract}
Atmospheric changes have been sporadic over the previous decade. Because of this in late period, atmosphere shrewd techniques called as savvy agribusiness is embraced by numerous Indian farmers. Keen farming is a robotized and coordinated data innovation executed with the Internet of Things. IOT is growing quickly and broadly connected in every remote condition. This paper presents an efficient sensor innovation and remote systems coordination of IOT innovation has been contemplated and looked into in light of the real circum-stance of agricultural activities. Real goal is to gather ongoing information of agriculture that gives simple access to the farmer. Our task screens the yield development utilizing advanced means giving the precise esteems of different parameters where upon the development depends. Additionally, it will help the farmer to screen more than one rural field in the meantime. Since, the vast majority of the observ-ing is done remotely, it will help the person to pick up data. Since, observing through our framework requires less labor, individuals with physical handicaps can be utilized for checking fields. Our task, not just tries to relieve the primitive methods identified with farming yet additionally serve the group by opening new roads for work.
\end{abstract}

Keywords: Internet of Things; Agriculture Monitoring; Wireless Sensor Networks.

\section{Introduction}

The Internet of Things (IoT) implies the use of cleverly related devices and structures to utilize data collected by embedded sen-sors and actuators in machines and other physical things. This is required to spread immediately completed the coming years and this joining will discharge another estimation of organizations that improve the individual fulfilment of clients and gainfulness of endeavors. Connectivity engages Internet of Things by uniting ordinary items. Availability of these articles is critical in light of the fact that basic protest level collaborations contribute towards aggregate insight in IoT organize. The IoT will build the scope of administrations, each requiring shifting levels of data transfer capacity, portability and idleness. For instance, benefits that are identified with open wellbeing or individual security will by and large require low dormancy, however not high data transfer capac-ity in essence. On the other hand, benefits that give reconnaissance may likewise require high data transmission. The IOT wouldn't be conceivable without sensors which will identify or measure any adjustments in the earth to produce information that can give an account of their status or even connect with nature. Detecting innovations give the way to make capacities that mirror a genuine familiarity with the physical world and the general population in it. The agriculture in India is as of now confronting a troublesome stage. India is moving towards and agriculture crisis because of deficient interest in irrigational and agrarian framework, absence of consideration, inadequate land management, non-given of rea-sonable costs to ranchers for crops and lacking area change in India. Our paper helps farmers for agriculturists for horticulture informatics and services. Our proposed framework is helpful in observing the field information and in addition controlling the field activities which gives flexibility.
Controlling of every one of these tasks will be through remote sensor systems associated with Internet and will be dealt with and performed by interfacing sen-sors. In this framework, we utilize different sensors for estimating the field condition.

\section{Related work}

In Smart Agricultural monitoring system, various wireless sensors are used. This framework permits information examination and customized through an application or by the page data. The me-chanical advancement in Wireless sensor systems made it con-ceivable to use in checking and control of field parameters. In view of the current review, it is discovered that yield of agriculture is been decreasing step by step. Utilization of innovation in the field of horticulture assumes essential part in the expanding the creation, and additionally in diminishing the labor endeavors. This system wants to cope up to the used sensors at appropriate areas for checking parameters is executed. Remote sensor systems measure the parameters of temperature, dampness, water level, soil dampness. The data collected from these sensors are connect-ed to the microcontroller. The received information is confirmed with the threshold values. On the off chance that the information surpasses the edge esteems, the LED begins to blink. What's more, right away, instant alert messages are been sent to the farmer and consequently he can work the field conditions by checking the produced webpage outcomes and description of the values in de-tail. In the proposed framework, correspondence signals from the sensor system and water system controlling were effectively inter-faced progressively. The obtained results can be figured out using Thing Speak app which shows to which extent the crop conditions are been functioning. Through this technology, agriculture production can be developed and simultaneously it reduces the man power. 


\section{Proposed system}

The implemented framework comprises of different sensors and devices and they are interconnected by means of remote corre-spondence modules. The sensor data is been sent and received from client end utilizing Internet connectivity which was enabled in the Node MCU module-an open source IoT platform. This sys-tem is used to maintain the optimal conditions of the irrigation system effectively. The data can be viewed on the Thing Speak app or any web page. The farmer can go through each and every information regarding the levels, at what time it's been function-ing, any fluctuations appearing or not, whether the operations are been performed in time.

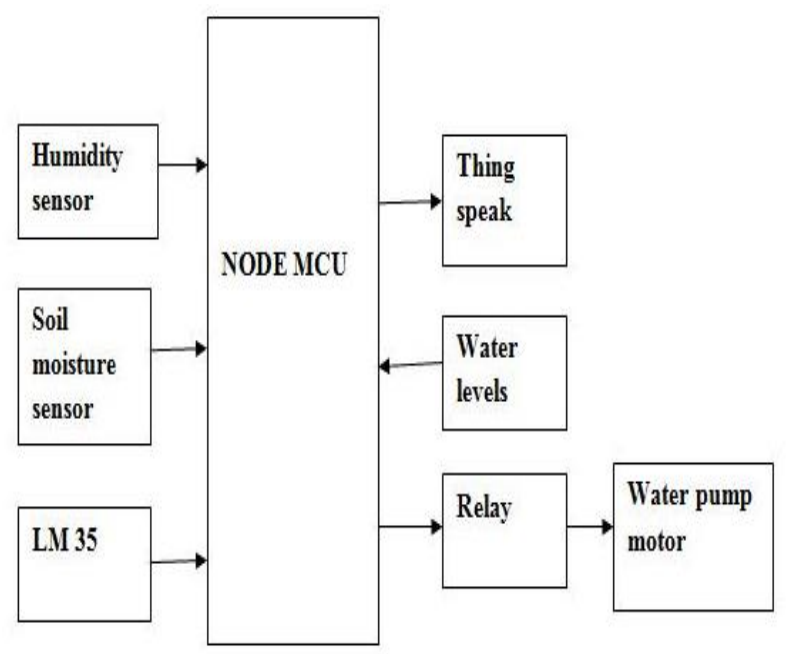

Fig. 1: System Architecture.

\section{Hardware requirement}

- $\quad$ Node MCU V3

- Soil Moisture Sensor

- Humidity Sensor

- LM35 Temperature Sensor

- Water Level Sensor

- BC547 Transistor

- Relay

\subsection{Node MCU}

Node MCU V3 is an open source IoT stage. It utilizes the Lua scripting dialect. The Lua venture is the premise of board, and based on the ESP8266 SDK 1.4. This utilizes many open sources and continues running on the ESP8266 Wi-Fi Source module where ESP8266 is a straightforwardness Wi-Fi chip.

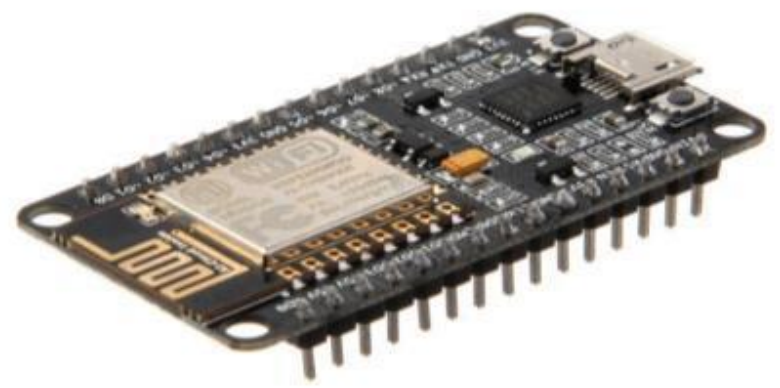

Fig. 2: Node MCU V3.

\subsection{Soil moisture sensor}

It senses the moisture content of the soil. The sensor has both analog and the digital output and works on the principle of open and short circuit. In this system, the output is high or low showed by the LED.
At the point when the soil is dry, there will no pas-sage of current and act as an open circuit. When soil is wet, the passage of current exists and circuit is said to be shot and the out-put will be zero. Sensor information is appeared by the levels. It is hostile to rust so the sensor has long life time which will manage the cost of the farmer at the very least cost.

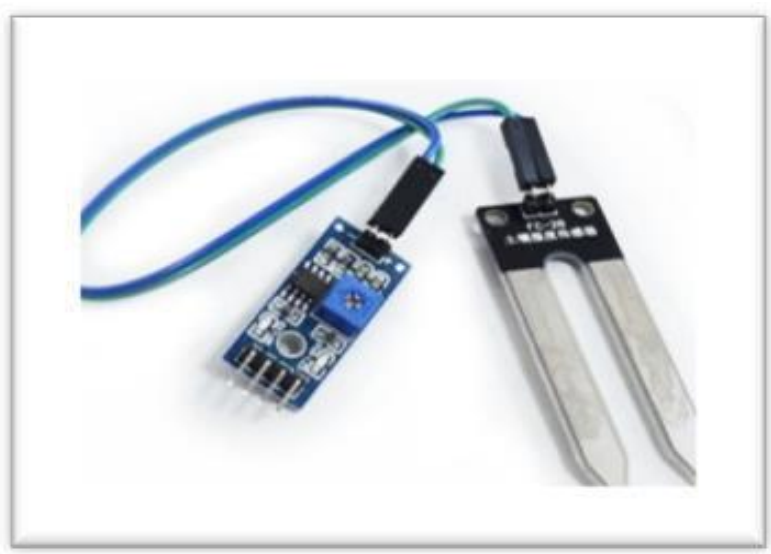

Fig. 3: Soil Moisture Sensor.

4.3 Humidity Sensor

Humidity sensed the proximity of water in air. The measure of water vapor in air can impact human comfort and what's more collecting frames in wanders. The closeness of water vapor in like manner impacts diverse physical, substance, and characteristic techniques. In this system, it shows the information at which level it was functioning. Suppose, it is under the level of 2, the second LED will starts blinking and instantly the values appears on the webpage and the farmer gets to know.

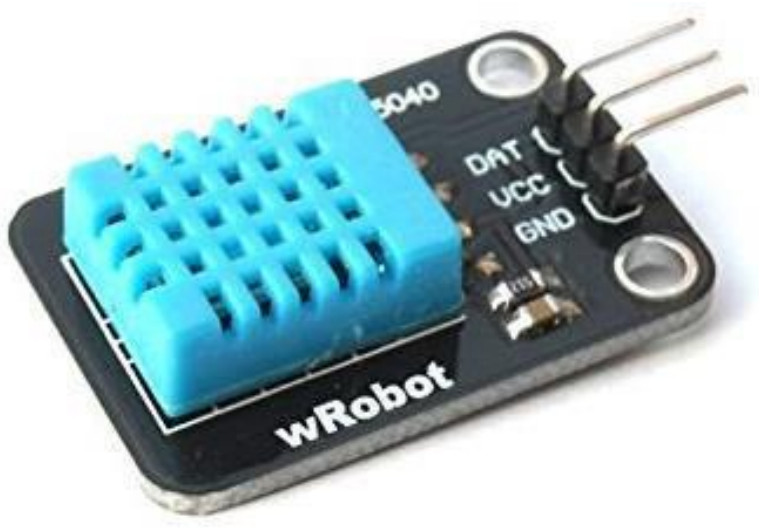

Fig. 4: Humidity Sensor.

\subsection{Temperature sensor- LM35}

This sensor is profoundly utilized in light of the fact that its output voltage is straight with Celsius scaling of temperature. It doesn't give any external trimming. It has a wide working extent. The maximum output is $5 \mathrm{~V}$. It has three terminals as Vcc, Ground and the simple sensor. It devours least measure of power. In this way, it is vitality efficient and user-friendly. Based on its levels, it shows the values. 


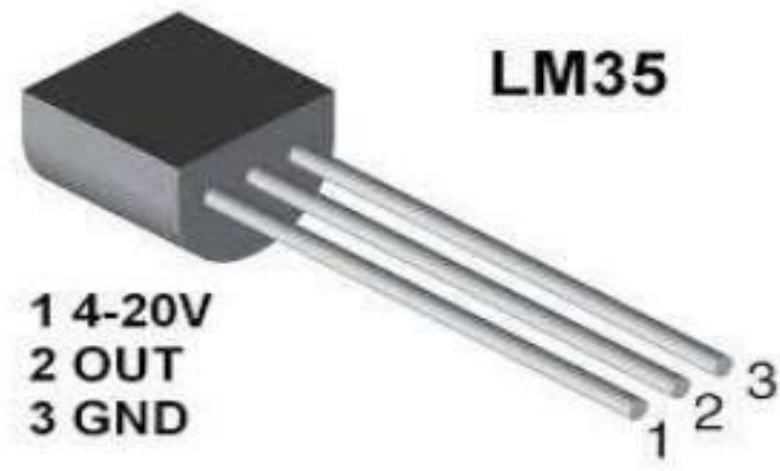

Fig. 5: Temperature Sensor.

\subsection{Water level sensor}

Water source is fundamental and an essential factor in agrarian and cultivate creation and is a key of our personal satisfaction also. Observing water level of a water source, for example, water tank or bore well and so forth. In this system, the sensor senses the water level, when it is at the level of 3, the third LED blinks and the farmer receives the information.

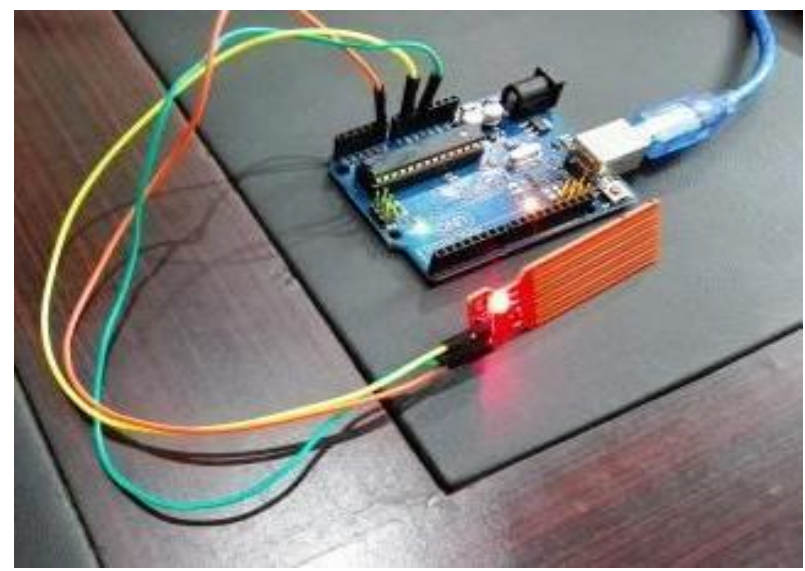

Fig. 6: Water Level Sensor.

\subsection{BC 547 transistor}

It is a NPN transistor subsequently the gatherer and producer will be left open (Reverse one-sided) when the base stick is held at ground and will be shut when a flag is given to base stick. BC547 has a pick up estimation of 110 to 800 ; this esteem decides the intensification limit of the transistor. The most extreme measure of current that could course through the Collector stick is 100mA.

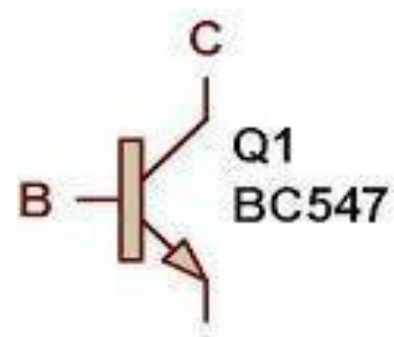

$\mathrm{E}$

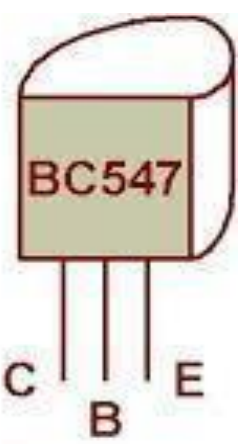

\subsection{Relay}

It is a switch which is electrically operated switch. For control-ling purpose the relay is used. It has the particular low-power signal.

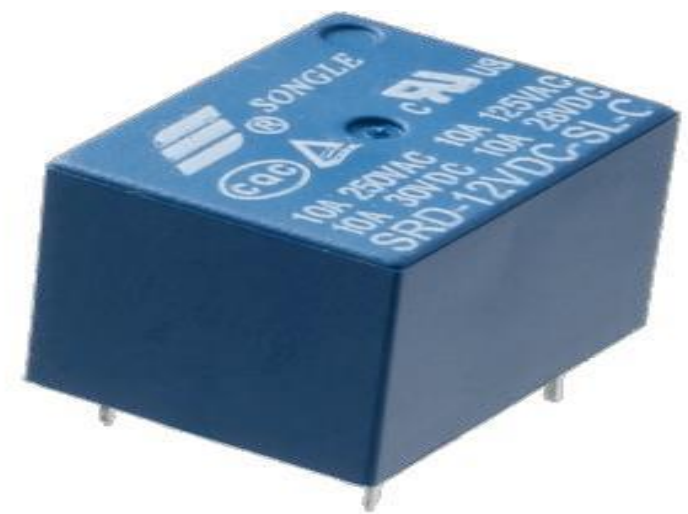

Fig. 8: Relay.

\section{Software used}

- $\quad$ Arduino UNO Software (IDE)

- Thing Speak Cloud platform

\subsection{Arduino IDE}

The Arduino Integrated Development Environment - or Arduino Software (IDE) - contains a word processor for creating code, a message zone, a substance console, a toolbar with gets for typical limits and a movement of menus. It partners with the Arduino and Genuino hardware to exchange programs and talk with them. Undertakings made using Arduino Software (IDE) is called diagrams. These portrayals are formed in the word processor and are saved with the report extension .ino. The editor has features for cutting/staying and for looking/supplanting content. The message zone gives input while saving and exchanging and moreover indi-cates botches. The solace indicates content output by the Arduino Software (IDE).

\subsection{Thing speak}

Thing Speak is an application stage for the Internet of Things that enables you to construct an application around information gathered by sensors. It includes constant information gathering, information handling, perceptions, applications, and modules.

\section{Experimental results}

The hardware is interfaced with all the sensors in the board. The sensors give input to the controller and farmer receives the data on the cloud platform in detail. Test results shows that the hardware can be controlled remotely using wireless network technology.

The following are the results viewed on the web page (also can be seen in Thing speak cloud platform). It clearly gives us the information regarding the sensor level, at what time crop conditions is been changing and date too. By this data, it becomes easy for a common man to understand.

\section{C-collector \\ B-Base \\ E-Emitter}

Fig. 7: BC 547 Transistor. 


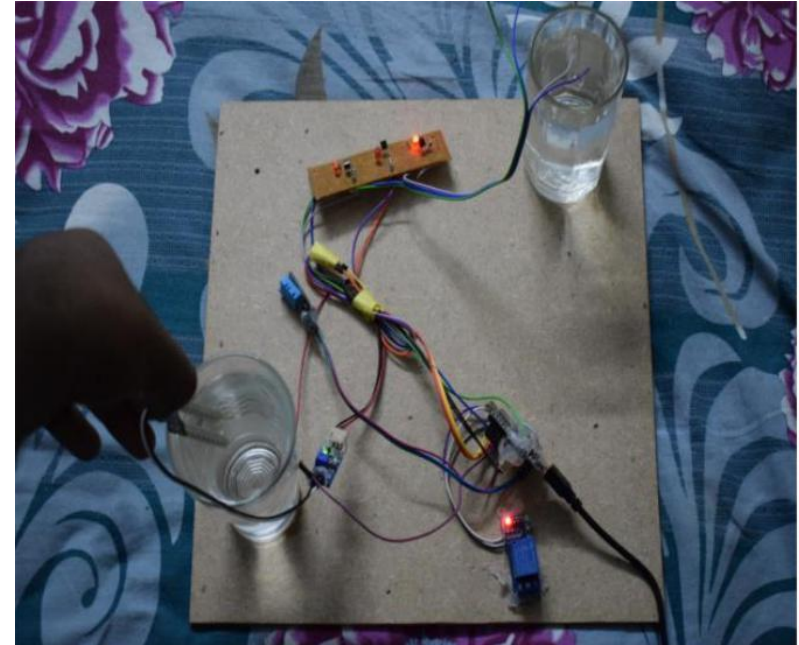

Fig. 9: Hardware Implementation.

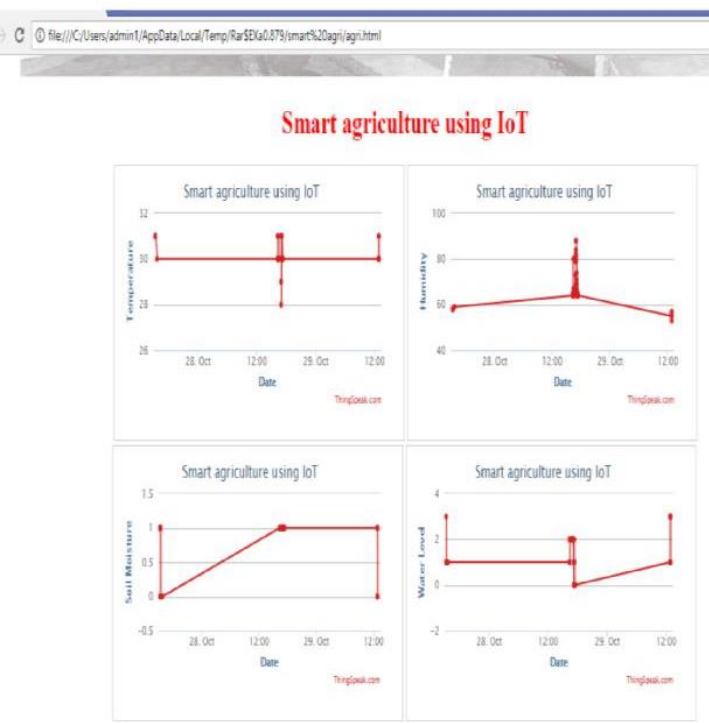

Fig. 10: Webpage Results.

\section{Future work and conclusion}

Our implemented system not only tries to mitigate the primitive techniques related to agriculture but also serve the community by opening new avenues for employment. The foremost function is to monitor the crop growth using digital means. This will provide the accurate values of various parameters upon which growth depends. Besides, it will help the farmer to monitor more than one land at the same time. Since, most of the monitoring is done remotely; it helps the farmer to gain information. Monitoring through our system requires less man power, people with physical disabilities can be employed for monitoring fields.

\section{Acknowledgement}

We express our sincere thankfulness to our project guide Dr.N.V.K. Ramesh for his successful guidance to our project. Without his help, it would be a tough job to accomplish. We thank our guide for his encouragement throughout out period of work. We also thank our Head of the Department (ECSE) Dr. K. Raghava Rao for providing us all the necessary facilities.

\section{References}

[1] P. Rajalakshmi, S. Devi Mahalakshmi, "IOT Based Crop-Field Monitoring and Irrigation Automation" in 10th International con-ference on Intelligent systems and control (ISCO) 7-8 Jan 2016, published in IEEE Xplore, Nov 2016.

[2] Tanmay Baranwal, Nitika Pushpendra Kumar Pateriya, "De-velopment of IoT based Smart Security and Monitoring Devices for Agriculture" in 6th International Conference - Cloud System and Big Data Engineering, IEEE,2016.

[3] Nelson Sales, Artur Arsenio, "Wireless Sensor and Actuator System for Smart Irrigation on the Cloud" published in IEEE Xplore, jan 2016.

[4]Mohamed Rawidean Mohd Kassim, Ibrahim Mat, Ahmad Nizar Harun, "Wireless Sensor Network in Precision agriculture application" in International conference on computer Information and telecommunication systems (CITS), published in IEEE Xplore, July 2014.

[5] Gayatri Londhe et al., "Automated Irrigation System By Using ARM Processor", IJSRET 2014.

[6] Yiming Zhou et al., "A Wireless Design of Low-Cost Irriga-tion System Using ZigBee Technology", IEEE 2009 International Conference on Networks Security Wireless Communications and Trusted Computing.

[7] I.F. Akyildiz, W. Su, Y. Sankarasubramaniam, E. Cayirci, "A survey on sensor networks" in IEEE Communications Magazine. 